\title{
Perfil das intoxicações exógenas notificadas em hospitais públicos
}

\author{
Profile of exogenous poisonings reported in public hospitals \\ Perfil de intoxicaciones exógenas notificadas en hospitales públicos
}

João Vitor Cardoso Moraes ${ }^{1}$, Larissa Silva Martins ${ }^{1}$, Letícia Maria Machado Coelho', Maria Tereza Duca Dantas Lima ${ }^{1}$, Sabrina Viscondi Lopes e Moura ${ }^{1}$, Vitória Caroline Prietoํ, Ivana Araújo, Roberta Bessa Veloso Silva1, Gérsika Bitencourt Santos ${ }^{1 *}$.

\section{RESUMO}

Objetivo: Identificar as principais características das intoxicações exógenas em pacientes atendidos em hospitais públicos. Métodos: Foram colhidos dados a partir do Sistema de Informação de Agravos de Notificação (SINAN/SES/MG), que revelaram o tipo e a incidência dos casos durante os anos de 2018 e 2019. As variáveis investigadas foram: exposição ao agente tóxico no ambiente de trabalho, evolução clínica do estado de intoxicação, agente tóxico utilizado, tipo de exposição pelo agente tóxico, circunstância em que o agente tóxico foi utilizado e faixa etária acometida pela intoxicação. Resultados: Dentre os tipos de envenenamento, é predominante a intoxicação aguda-única (79), aguda-repetida (25), casos ignorados/não preenchidos nos prontuários (10) e um caso isolado de intoxicação crônica (1). As circunstâncias analisadas e suas incidências: uso habitual (4), ignorado e não preenchido no relatório (3), uso habitual (7), acidental (9), erro de administração (1), ingestão de alimento contaminado (2), tentativa de autoextermínio (90), violência/homicídio (2), entre outras circunstâncias (1), com um total de 115 notificações. Considerações finais: Em geral, o envenenamento é agudo-único, decorrente de tentativa de autoextermínio. Demonstra-se a importância de novas pesquisas, para que o profissional de saúde consiga intervir no diagnóstico e também no tratamento adequado, criando políticas públicas efetivas.

Palavras-chave: Toxicidade, Exposição ao risco, Compostos químicos, Sistemas de informação em saúde.

\section{ABSTRACT}

Objective: To identify the main characteristics of exogenous intoxications in patients treated at public hospitals. Methods: Data were collected from the Notifiable Diseases Information System (SINAN/SES/MG), revealing the type and incidence of cases during the years 2018 and 2019. The variables investigated were: exposure to the toxic agent in the workplace, clinical evolution of the intoxication state, toxic agent used, type of exposure by the toxic agent, circumstance in which the toxic agent was used and age group affected by the intoxication. Results: Among the types of poisoning, acute-single poisoning (79), acute-repeated poisoning (25), ignored / unfilled cases in the medical records (10) and an isolated case of chronic poisoning (1). The circumstances analyzed and their incidences: usual use (4), ignored and not filled out in the report (3), usual use (7), accidental (9), administration error (1), ingestion of contaminated food (2), attempt self-extermination (90), violence / homicide (2), among other circumstances (1), with a total of 115 notifications. Final considerations: In general, the poisoning is acute-unique, resulting from an attempt at self-extermination. The importance of new research is demonstrated, so that the health professional is able to intervene in the diagnosis and also in the appropriate treatment, creating effective public policies.

Key words: Toxicity, Risk exposure, Chemical compounds, Health information systems.

${ }^{1}$ Universidade José do Rosário Vellano (UNIFENAS), Alfenas - MG. *E-mail: gersika.bitencourt@unifenas.br SUBMETIDO EM: 3/2021

PUBLICADO EM: 4/2021 


\section{RESUMEN}

Objetivo: Identificar las principales características de las intoxicaciones exógenas en pacientes atendidos en hospitales públicos. Métodos: Se recolectaron datos del Sistema de Información de Enfermedades Notificables (SINAN/SES/MG), revelando el tipo e incidencia de casos durante los años 2018 y 2019. Las variables investigadas fueron: exposición al agente tóxico en el lugar de trabajo, evolución clínica del estado de intoxicación, agente tóxico utilizado, tipo de exposición al agente tóxico, circunstancia en la que se utilizó el agente tóxico y grupo de edad afectado por la intoxicación. Resultados: Entre los tipos de intoxicación, intoxicación aguda-única (79), intoxicación aguda-repetida (25), casos ignorados / sin completar en la historia clínica (10) y un caso aislado de intoxicación crónica (1). Las circunstancias analizadas y sus incidencias: uso habitual (4), ignorado y no cumplimentado en el informe (3), uso habitual (7), accidental (9), error de administración (1), ingestión de alimento contaminado (2), intento de autoexterminación (90), violencia / homicidio (2), entre otras circunstancias (1), con un total de 115 notificaciones. Consideraciones finales: En general, el envenenamiento es agudo único, como resultado de un intento de autoexterminamiento. Se demuestra la importancia de las nuevas investigaciones, para que el profesional de la salud sea capaz de intervenir en el diagnóstico y también en el tratamiento adecuado, generando políticas públicas efectivas.

Palabras clave: Toxicidad, Exposición al riesgo, Compuestos químicos, Sistemas de información en salud.

\section{INTRODUÇÃO}

A intoxicação é uma situação grave que ocorre a partir da interação do organismo com substâncias químicas potencialmente tóxicas, desencadeando um processo de desequilíbrio fisiológico secundário a alterações bioquímicas. A causa está relacionada à exposição acidental ou intencional a substâncias como os agrotóxicos, drogas lícitas e ilícitas, alimentos, bebidas, plantas tóxicas e medicamentos (SANTOS RR, et al., 2015).

Apesar de serem um problema global, as intoxicações são distintas em cada país pelas diferenças geográficas, sociais, econômicas e culturais. Por suas propriedades curativas, paliativas e profiláticas, os fármacos surgem como base nos tratamentos da medicina convencional. Entretanto, o acesso fácil e o uso excessivo apontam os medicamentos como um dos principais agentes tóxicos causadores de intoxicação, tornando a exposição a essas substâncias um grave problema de saúde pública (GONÇALVES CA, et al., 2017; BAIOCCO GG, et al., 2020). A cultura da automedicação, ou seja, o uso de medicações sem orientação profissional é uma prática comum na sociedade (MORAES AL, et al., 2016).

Entre os medicamentos que mais aparecem nos relatórios de centros especializados no atendimento à intoxicações destacam-se os fármacos analgésicos, sedativos, antidepressivos, antimicrobianos, antihistamínicos e cardiovasculares, além de suplementos vitamínicos e minerais. Entretanto, os órgãos públicos de saúde ainda enfrentam o problema da subnotificação dos casos de intoxicação exógena, fator que dificulta o rastreamento do perfil epidemiológico dos envenenamentos de acordo com o tipo de substância utilizada (GONÇALVES CA, et al., 2017).

Conforme Portaria ํㅜ 1.061, de maio de 2020, são notificados agravos de notificação compulsória, como os casos de intoxicação exógena. Todos esses incidentes devem ser relatados e submetidos à avaliação epidemiológica, para que seja possível traçar o perfil dos pacientes mais acometidos por envenenamentos, a fim de impedir a camuflagem do problema. Dessa maneira, o objetivo desta pesquisa foi identificar as principais substâncias causadoras das intoxicações exógenas em pacientes atendidos em hospitais públicos, em Alfenas, Minas Gerias, no período de 2018 e 2019, através do banco de dados do Sistema de Informação de Agravos de Notificação (SINAN).

\section{MÉTODOS}

Este é um estudo observacional e transversal, oriundo de uma pesquisa descritiva de dados epidemiológicos de origem secundária, que analisa os registros de casos de intoxicações exógenas atendidos 
em hospitais públicos localizados em Alfenas - MG, nos anos de 2018 e 2019, pelo serviço de clínica médica do hospital. Foram coletadas informações clínicas e sociodemográficas para uma análise mais profunda.

A coleta de dados foi realizada pelos próprios pesquisadores e as variáveis utilizadas foram: exposição ao agente tóxico no ambiente de trabalho, evolução clínica do estado de intoxicação, agente tóxico utilizado, tipo de exposição pelo agente tóxico, circunstância em que o agente tóxico foi utilizado e faixa etária acometida pela intoxicação. Os critérios de inclusão envolveram todos os registros de intoxicações exógenas notificados pelos hospitais ao SINAN. As variantes empregadas foram importantes para que fosse possível traçar o perfil epidemiológico das intoxicações exógenas dos pacientes em questão.

A partir da coleta dos dados, foi realizada uma análise observacional e descritiva, utilizando-se as médias para o cálculo das variáveis contínuas obtidas. Para a análise dos dados utilizou-se o teste de qui-quadrado, ao nível nominal de $5 \%$ de significância para verificar a existência de associação entre as variáveis analisadas. O teste exato de Fisher foi aplicado nos casos em que a frequência absoluta das células da tabela de contingência foi menor ou igual a 5 . Os dados foram organizados e apresentados pelo gráfico de barras. A análise estatística foi realizada no software R (R CORE TEAM, 2020).

\section{RESULTADOS E DISCUSSÃO}

As mulheres tiveram maior incidência de intoxicação exógena com 71 (61,7\%) dos casos relatados neste estudo, referente aos anos de 2018 e 2019. Resultado condizente com o encontrado no trabalho de Veloso C, et al. (2017), que analisaram as violências auto infligidas por intoxicação exógena no período de 2009 a 2014 e constataram que o maior número de tentativas de suicídio ocorreu com o sexo feminino, alegando a vulnerabilidade deste grupo quanto à violência doméstica, abuso sexual, maior acometimento frente a estressores psicossociais e ao desenvolvimento de psicopatologias, além dos aspectos culturais (Gráfico 1).

Melo CM, et al. (2020) também constou tal vulnerabilidade ao relacionar registros de violência doméstica com a tentativa de suicídio de mulheres por intoxicações exógenas, sendo constatada a maior probabilidade de mulheres em situações de violência causada por seus parceiros tentarem suicídio pelo menos uma vez. Por outro lado, algumas pesquisas relatam a maior incidência de intoxicações exógenas em mulheres advinda do uso acentuado de medicamentos pelo fator cultural de maior preocupação com a saúde em contraste com a resistência masculina em procurar ajuda médica (TIMÓTEO MVF, et al., 2020).

Gráfico 1 - Notificações por Ano e Sexo, referente aos anos de 2018 e 2019.

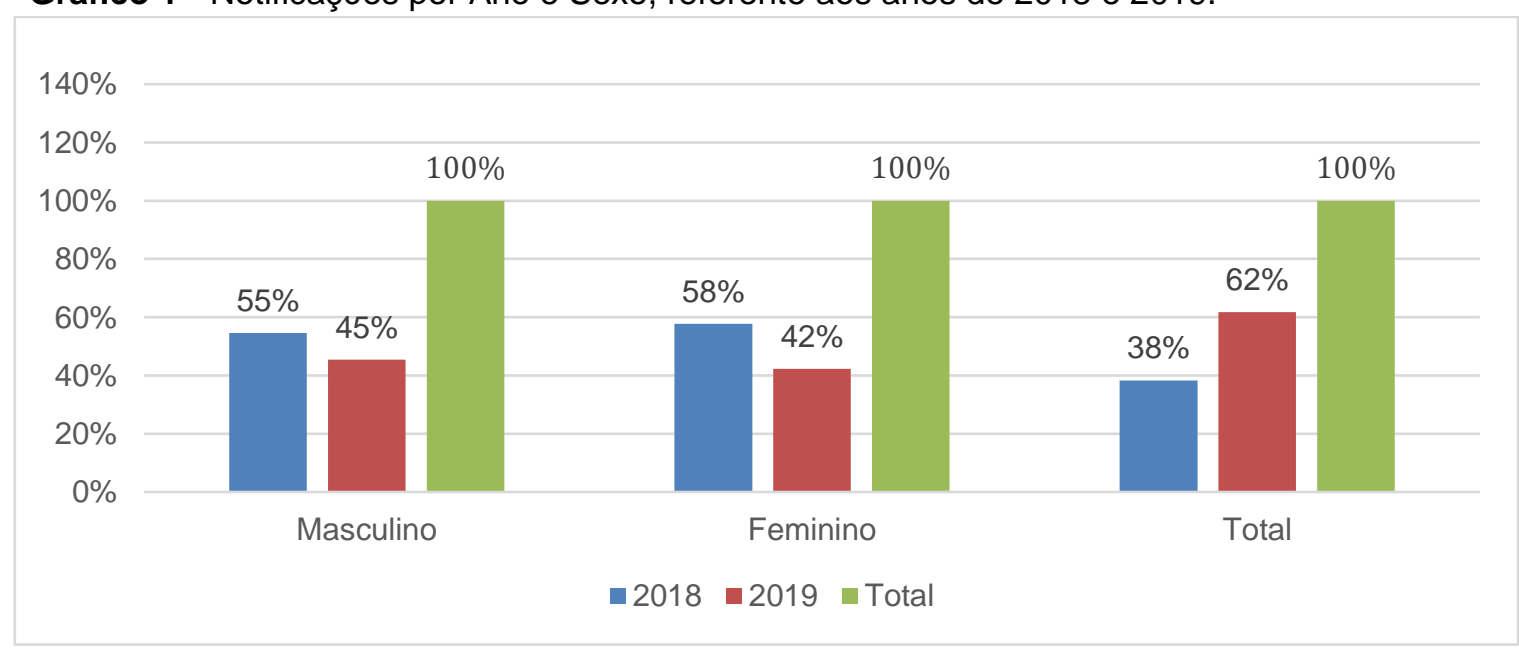

Fonte: Moraes JVC, et al., 2021.

A faixa etária predominante no ano de 2018 foi de 20 a 29 anos, com 33,8\% das notificações ( $n=22$ ), seguida da faixa etária de 15 a 19 anos, com 18,4\% ( $n=12)$. De 30 a 39 anos, observou-se $16,9 \%$ dos casos $(n=11)$, dos 40 aos 49 anos, 9,2\% (n=6), 1 a 4 anos com 6,1\% (n=4), 10 a 14 anos com 4,6\% (n=3) e 50 a 59 
anos também com 4,6\% (n=3). Dos 60 aos 69 anos, foram registrados $3 \%$ das notificações $(n=2)$, de 5 a 9 anos com $1,5 \%(n=1)$ e de 70 a 79 anos também com $1,5 \%$ dos casos notificados $(n=1)$, sendo as mulheres mais acometidas por intoxicações exógenas, em um total de 41 dos 65 casos notificados (63\%).

No ano de 2019, a faixa etária predominante também foi a dos 20 aos 29 anos, mas com redução de $36 \%$ no número de casos, apresentando um total de $28 \%$ do total $(n=14)$, seguida da faixa etária dos 15 aos 19 anos, com $16 \%(n=8)$ e dos 40 aos 49 anos também com $16 \%$ do total de casos $(n=8)$. De 1 a 4 anos, a porcentagem de casos foi de $8 \%(n=4)$, assim como de 50 a 59 anos, $8 \%(n=4)$. Por fim, as menores incidências foram das faixas etárias de 10 a 14 anos, $6 \%(n=3)$, menor de 1 ano, com $4 \%(n=2)$ e de 5 a 9 anos, $2 \%(n=1)$ (Gráfico 2).

A partir da coleta e análise dos dados do SINAN, nos anos 2018 e 2019 houve maior incidência de intoxicações entre os jovens de 20 a 29 anos no município, representando $31,3 \%$ do total. Este padrão analisado é convergente com o encontrado no trabalho de Nakajima NR, et al. (2019), os quais analisaram a epidemiologia das intoxicações exógenas na região do triângulo mineiro. Desta maneira, notou-se que jovens e adultos são mais suscetíveis às intoxicações exógenas, isso pois de acordo com Ferreira DS, et al. (2014) o predomínio de intoxicações nesta faixa etária tem como causa primordial suicídios, ocasionados pela maior vulnerabilidade aos conflitos e problemas relacionais desses indivíduos para com suas vidas.

De acordo com outros estudos, as crianças, especialmente menores de três anos de idade, são vulneráveis à intoxicação acidental, assim como as pessoas idosas, os pacientes hospitalizados e os trabalhadores da agricultura pecuária e da indústria (LIBERATO AA, et al., 2017). Em contrapartida, de acordo com o estudo de Oliveira FF, et al. (2014) as intoxicações que ocorreram em 2010, tinham predominância de crianças e adolescentes, mas após este período houve uma diminuição dos casos graças a iniciativas mais eficientes de saneamento básico, higiene, alimentos processados, fiscalização governamental e medidas educativas e preventivas.

Gráfico 2: Faixa etária predominante nos envenenamentos referente aos anos de 2018 e 2019.

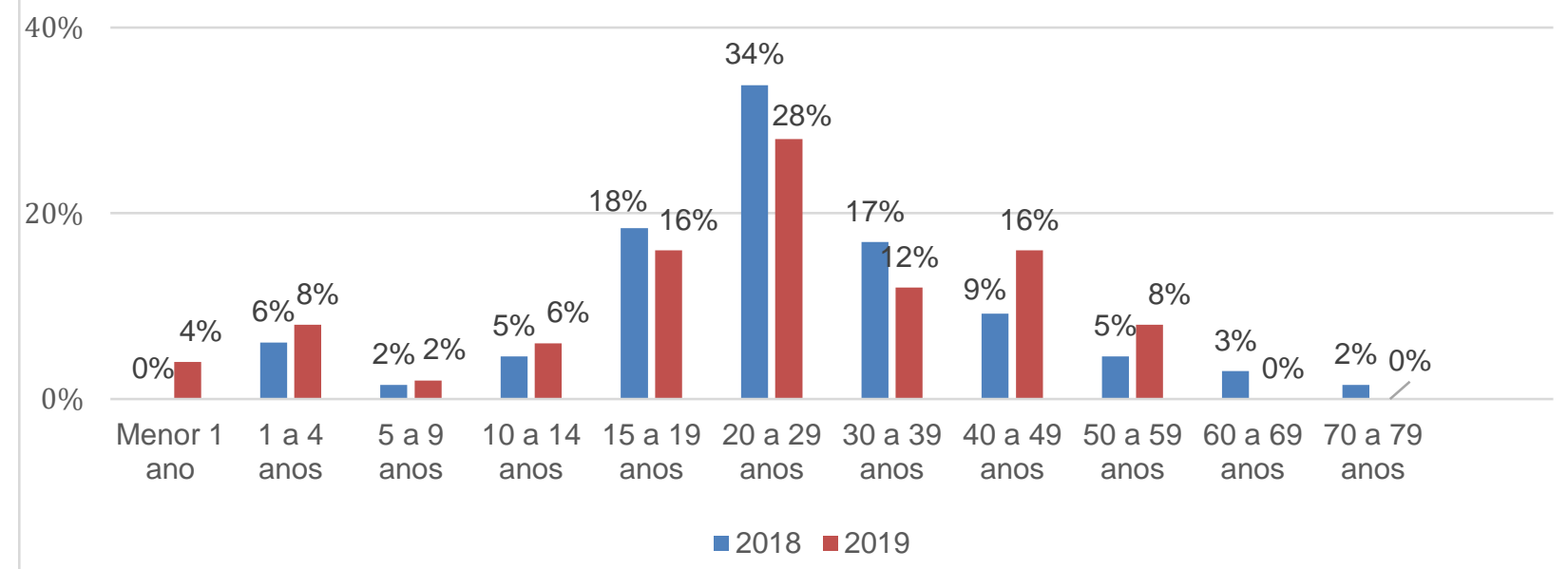

Fonte: Moraes JVC, et al., 2021.

É importante verificar que o perfil mais acometido por intoxicações exógenas foi o de mulheres entre 15 e 29 anos. Uma possível hipótese para este comportamento foi a tentativa de autoextermínio relatada no estudo de Trevisan EPT, et al. (2012), os quais demonstraram que as mulheres são mais suscetíveis a tentativa de autoextermínio por métodos não violentos, como por exemplo, através do envenenamento, uma vez que o grande motivo dessa tentativa de autoextermínio, na maioria das vezes, é acabar com o sofrimento físico ou psicológico que a acomete, e não acabar com a própria vida, diferentemente de homens, sendo assim identificada uma demarcação de questões de gênero no suicídio. 
No ano de 2018, a quantidade de intoxicações em relação ao agente tóxico utilizado foi: por medicamentos $(n=41)$, raticida $(n=5)$, produto de uso domiciliar $(n=2)$, produto químico $(n=4)$, pesticidas agrícolas $(n=1)$, drogas de abuso $(n=1)$, alimentos e bebidas $(n=1)$, outros $(n=1)$ e ignorado/branco $(n=9)$, onde não foi possível identificar a utilização da substância responsável pela intoxicação. Não foram registrados casos de envenenamento por produto veterinário. No ano de 2019, ocorreu uma defasagem de registros em relação ao agente tóxico, obtendo 38 registros em 50 casos notificados, sendo: agrotóxico agrícola $(n=2)$, produto veterinário $(n=2)$, raticida $(n=1)$, ignorado/branco $(n=7)$ e os demais agentes apresentados no ano anterior, não tiveram nenhum registro. Uma limitação do estudo são os casos notificados como ignorados ou brancos, que podem estar relacionados ao preenchimento pelos profissionais responsáveis, sendo necessário melhorar a qualidade de preenchimento do sistema para que a análise tenha dados com maior confiabilidade.

O município apresentou aumento anual dos registros de intoxicações exógenas apenas pelos agentes de agrotóxicos agrícolas $(n=2)$ e produtos veterinários $(n=2)$. Este resultado se difere do que o estado de Minas Gerais apresentou nas notificações do Departamento de Informática do Sistema Único de Saúde (DATASUS) no período de 2016 a 2017, o qual só relatou decréscimo nos agentes alimentos e bebida (CARVALHO FSA, et al., 2017).

O número de registros de intoxicação exógena por medicamentos superou os demais agentes em dezenas de casos. Esse fato também foi encontrado por outros autores, Nakajima NR, et al. (2019), na análise das intoxicações exógenas no triângulo mineiro, mostraram que os medicamentos foram a causa de $2 \%$ das intoxicações $(n=72)$. Em Juiz de Fora, também obtiveram os mesmos resultados. Assim, pode-se sugerir que os medicamentos contribuíram com uma maior porcentagem nas intoxicações por serem acessíveis à população, além de possuírem maior toxicidade, dependendo da dose ingerida (SILVA RLF, et al., 2017).

Os danos à saúde podem decorrer da multiplicidade de formas de exposição, sendo que as intoxicações agudas tendem a ter maior visibilidade nos serviços de urgência e emergência (PRÜSS-USTÜN A; VICKERS C; HAEFLIER P, et al., 2011). No ano de 2018, apresentaram-se os resultados dos seguintes tipos de exposições com suas respectivas incidências: aguda-única (52), aguda-repetida (7), ignorado/branco, no qual o tipo de intoxicação não foi informado (6) e nenhum caso de intoxicações do tipo crônica, totalizando 65 notificações. No ano de 2019: aguda-única (27), aguda-repetida (18), ignorado/branco (4) e 1 caso tipo crônico, com um total de 50 casos notificados neste ano. Dessa maneira, concluiu-se que a maior parte das intoxicações exógenas foi do tipo aguda-única, com 79 dos casos totais concentrando-se mais no ano de 2018 ao representar $80 \%$ das notificações (Gráfico 3).

Gráfico 3 - Notificações de acordo com o tipo de exposição em relação aos anos de 2018 e 2019.

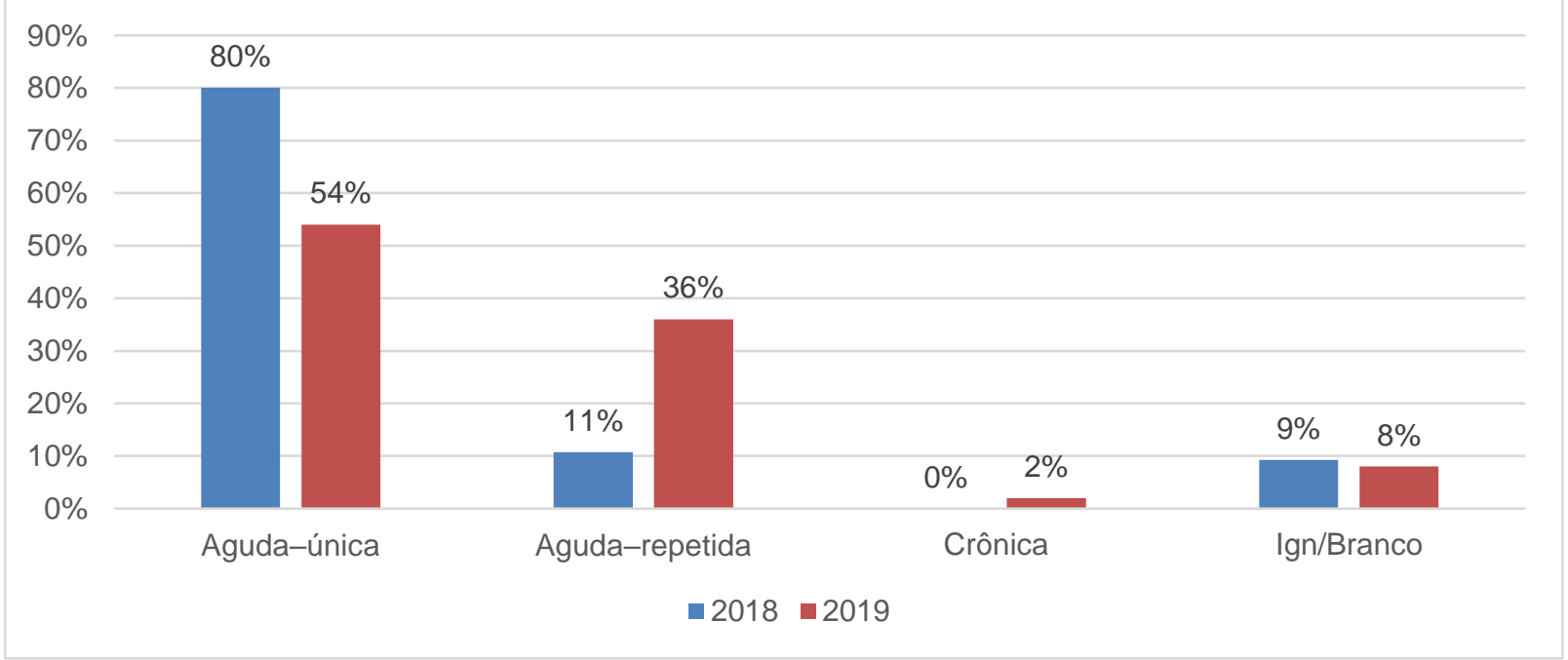

Fonte: Moraes JVC, et al., 2021.

As intoxicações agudas únicas que se mostraram predominantes na região no ano de 2018 , definem-se quando há uma única intoxicação do paciente, nessas os sintomas surgem de forma súbita, alguns minutos 
ou nas horas subsequentes após a exposição ao agente químico, podendo ocorrer de forma leve, moderada ou grave. As agudas repetidas ocorrem quando há uma reincidência da intoxicação em um curto espaço de tempo (RODRIGO LCP e CEQUINEL JC, 2018).

Foi possível relacionar esse dado de intoxicações exógenas agudas (IEA) com o uso indiscriminado de medicamentos. A isso, ressalta-se que é considerado consenso na literatura a relação entre a facilidade do acesso aos medicamentos e automedicação no Brasil e, também devido a fatores econômicos e culturais (SANTOS RR, et al., 2015). O consumo de medicamentos reforça a necessidade de haver maior rigor na prescrição, dispensa e comercialização dos fármacos (RANGEL NL e FRANCELINO EV, 2018).

Em se tratando da circunstância e ano, verificaram-se as seguintes incidências em 2018: tentativa de suicídio (52), uso habitual (4), acidental (4), ingestão de alimento (2), violência/homicídio (1), outra (1), ignorado/branco, onde a exposição/circunstância não foi informada (1) e nenhuma tangente a erro de administração. No ano de 2019: tentativa de suicídio (38), acidental (5), uso habitual (3), violência/homicídio (1), erro de administração (1), ignorado/branco (2) e nenhuma dos tipo ingestão de alimento e outra. Com isso, percebeu-se que a maioria das circunstâncias analisadas foram de tentativas de suicídio, prevalecendo no ano de 2018 com $80 \%$ dos casos e $2019,76 \%$.

Esse padrão foi condizente com os dados de Veloso C, et al. (2017), ao revelarem que pesquisas nacionais e internacionais indicam intoxicações exógenas como principal meio de tentativas de suicídio, estando entre os três principais métodos de violência autoinflingida. Esse fato relatado também no trabalho de Rebelo FM, et al. (2011) no qual a análise apontou uma porcentagem de $43,8 \%$ dos casos. Foi relatado por Santos AS, et al. (2013), que são escassos os estudos sobre suicídios por intoxicação no Brasil, isso provavelmente pela frequência não elevada (16\%) comparando-se com outras formas como enforcamento $(60,1 \%)$. Apesar disso, essa taxa ainda se mostra relevante, superando métodos como o uso de armas de fogo (10,3\% em 2010).

No ano de 2018, obtiveram-se os seguintes critérios de confirmação: clínico $(n=58)$, clinico-laboratorial $(n=2)$, clínico-epidemiológico e ignorado/branco $(n=5)$, com nenhuma notificação, totalizando 65 notificações. No ano de 2019, os critérios de confirmação com seus respectivos números de notificação foram: clínico $(n=39)$, clínico-epidemiológico $(n=3)$, clinico-laboratorial $(n=2)$, ignorado/branco $(n=6)$, totalizando 50 notificações.

No período observado, os critérios de confirmação do tipo clínico representaram cerca de $84,3 \%$ das notificações. Este padrão difere-se do encontrado nas informações do sistema de informação de agravos de notificação (SINAN), extraído em 10 de julho de 2016, segundo o qual o critério de confirmação dos casos de óbito por IE que apresentou maior frequência, em 2014, no município de São Paulo, foi clínico-epidemiológico.

Em relação à intoxicação decorrente da exposição ao trabalho, o número de notificações foi pouco expressivo e contabilizou apenas 2 dos 65 casos relatados em 2018, e 3 dos 50 casos de 2019. Estes valores representaram 4,3\% do total, o que pode levar à hipótese de que grande parte dos casos não são notificados ao SINAN. Em consonância, essas subnotificações podem ser explicadas pelo fato de trabalhadores mais expostos às intoxicações exógenas serem os agricultores rurais, sendo moradores da zona rural que não buscam atendimento médico. Isso ocorre pela dificuldade tanto de acesso ao sistema de saúde e de funcionamento ineficaz em certos lugares, quanto de entender os sinais e sintomas da intoxicação como tais, por serem similares aos de problemas de saúde comuns como tontura, cefaleia e fadiga (SANTOS IND, et al., 2021).

No ano de 2018, a notificação de óbito por intoxicação exógena foi singular $(n=1)$, as notificações de cura com sequela representaram $3 \%(n=2), 15,3 \%$ ignorado/branco $(n=10)$, e $80 \%$ de notificações de cura sem sequela ( $n=52$ ), resultando em 65 notificações. No ano de 2019, não houve notificações de óbito e de cura com sequela. As notificações de evolução de cura sem sequelas foram de $74 \%(n=37)$ e ignorado/branco foram de $26 \%(n=13)$, obtendo 50 notificações totais (Gráfico 4).

Observando o artigo dos autores Gonçalves HC e Costa JB (2018), percebe-se que a prevalência em ambos é de cura sem sequelas e a menor frequência é a de óbitos. Há uma concordância entre os dados explorados e observa-se alta eficácia no tratamento dessas intoxicações exógenas, demonstrando certo êxito 
nos casos. Porém observa-se em nossos dados o índice de ignorado/Branco no total de $20 \%$ dos casos, o que gera dúvidas em relação a eficácia no registro e nas notificações dos casos.

Gráfico 4 - Evolução do quadro de intoxicação de acordo com o ano da notificação.

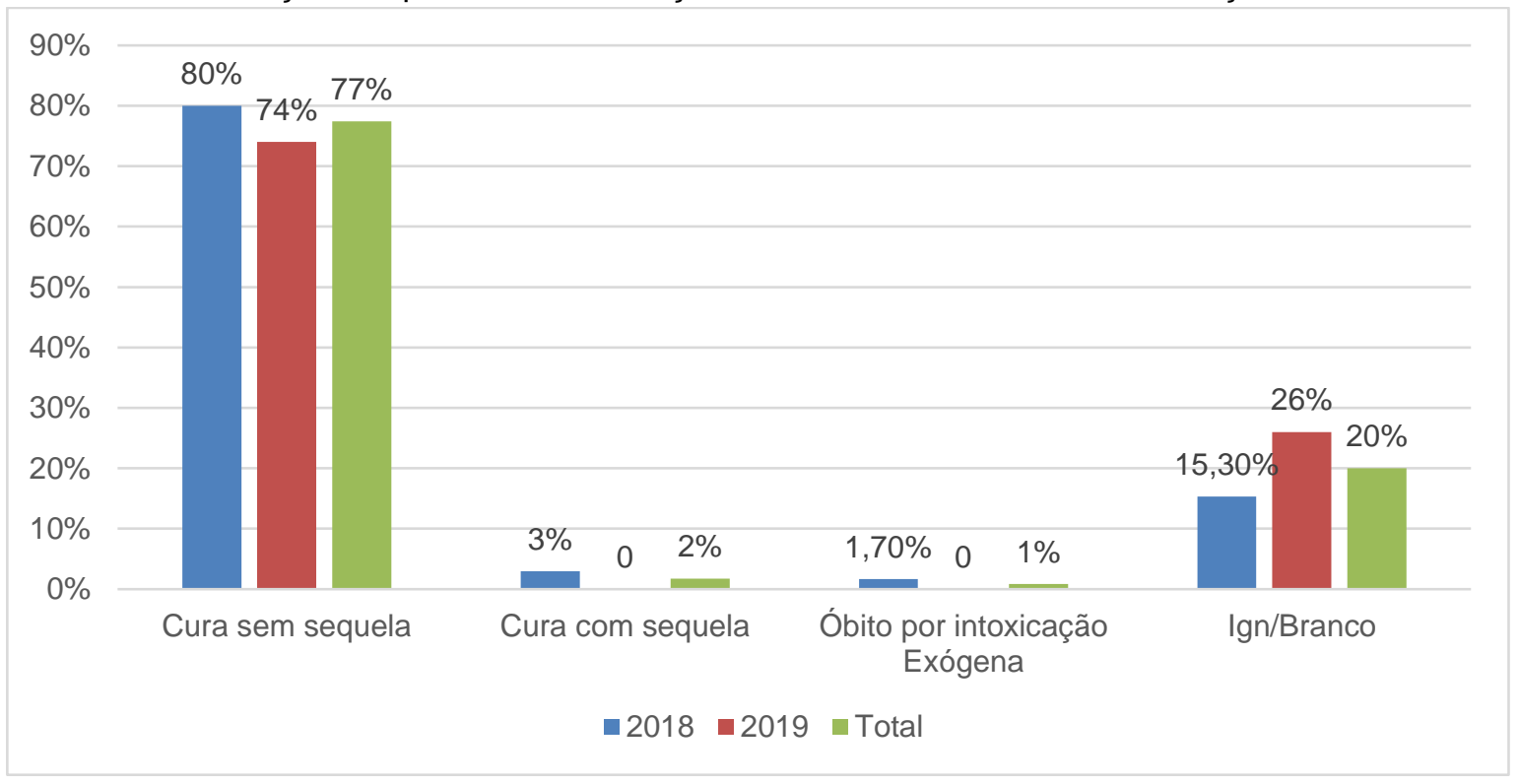

Fonte: Moraes JVC, et al., 2021.

O número total de notificações de intoxicações exógenas totais no ano de 2018 (65) excede ao de 2019 (50), porém, as notificações sem registro de evolução em 2019 foram maiores que as do ano anterior. Os resultados obtidos no município não foram condizentes com os dados dos anos anteriores (2016-2017) do estado de Minas Gerais, publicados pelo DATASUS, que mostraram aumento nas notificações registradas no estado (CARVALHO FSA, et al., 2017).

Foram apresentados os valores- $p$ resultantes da relação entre as variáveis de interesse. Pode-se observar que o tipo de notificação variou de acordo com os anos ( $p=0,0027)$. Para as demais variáveis relacionadas, não houve significância estatística $(p>0,05)$, porém mesmo não existindo associação significativa, algumas relações merecem discussão (Tabela 1).

Tabela 1 - Valores-p resultantes da associação entre as variáveis analisadas.

\begin{tabular}{c|c}
\hline Variáveis & Valor-p \\
\hline Anos versus gênero & $0,8863 \mathrm{~ns}$ \\
Faixa etária versus anos (2018 e 2019) & $0,7483 \mathrm{~ns}$ \\
Faixa etária versus gênero (2018) & $0,5112 \mathrm{~ns}$ \\
Faixa etária versus gênero (2019) & $0,2735 \mathrm{~ns}$ \\
Classificação versus anos (2018 e 2019) & $0,9574 \mathrm{~ns}$ \\
Critério de confirmação versus anos (2018 e 2019) & $0,1731 \mathrm{~ns}$ \\
Exposição trabalho versus anos (2018 e 2019) & $0,5396 \mathrm{~ns}$ \\
Evolução versus anos (2018 e 2019) & $0,2693 \mathrm{~ns}$ \\
Agente tóxico versus anos (2018 e 2019) & $0,1805 \mathrm{~ns}$ \\
Circunstância versus anos (2018 e 2019) & $0,7284 \mathrm{~ns}$ \\
Tipo de exposição versus anos (2018 e 2019) & $0,0027^{* *}$ \\
Tipo de exposição versus faixa etária & $0,9353 \mathrm{~ns}$ \\
\hline
\end{tabular}

Legenda: ${ }^{n s}$ Não significativo ao nível nominal de $5 \%$ de significância $(p>0,05)$.

Fonte: Moraes JVC, et al., 2021. 
Em se tratando do tipo de exposição e os anos (2018 e 2019), verificou-se que das 65 (56\%) notificações em 2018, 52 (80\%) foram do tipo aguda-única; 7 (11\%), aguda-repetida; 6 (9\%), ignorado/branco e $0(0 \%)$, crônica. Ao se comparar com o ano de 2019, dos 50 (44\%), 27 (54\%), apresentaram o tipo aguda-única; 18 (36\%), aguda-repetida; 4 (8\%), ignorado/branco e 1 (2\%), crônica.

Deve-se chamar a atenção para as variáveis circunstância e anos, apesar da não significância estatística $(p=0,7284)$. Dos $65(56 \%)$ casos notificados de intoxicação, no ano de 2018 e dos 50 (44\%), em 2019, as maiores frequências para tentativas de suicídio foram, respectivamente, $52(80 \%)$ e 38 (76\%).

O suicídio está entre as três principais causas de morte entre adolescentes e jovens, em média, cada vez que ele ocorre, cinco ou seis pessoas próximas a vítima são afetadas emocional, social e economicamente, constituindo um importante problema de saúde pública, relatado em diversos estudos (VIEIRA LP, et al., 2015). Segundo Vieira D, et al. (2016), no Brasil, circunstâncias relacionadas à prescrição médica e erros de administração são as maiores causas de intoxicações agudas únicas.

Ressalta-se a importância de conscientizar a população sobre o uso racional dos medicamentos, informando-a acerca dos riscos da automedicação, do uso do medicamento em doses exageradas, frequências e concentrações excessivas, além da identificação de prescrições médicas inadequadas. Portanto, é fundamental a procura de um profissional habilitado a fim de garantir o uso para a patologia correta e evitar o abuso de medicamentos, inclusive em tentativas de suicídio (LIMA JVO, et al., 2020).

\section{CONSIDERAÇÕES FINAIS}

Os resultados demonstram que existe uso de forma rotineira de produtos que são ou podem ter caráter tóxico entre a população estudada. Neste artigo foi observado que os medicamentos ocupam o primeiro entre todos os tipos de agentes tóxicos registrados, sendo o gênero feminino que mais se destacou. Levando em consideração as faixas etárias, pacientes com idade de 20 a 29 anos foram os de maior incidência. Em grande parcela da exposição à intoxicação exógena, demostrou-se que há como principal circunstância a intoxicação a intenção de suicídio. Este estudo mostra a importância de novas pesquisas na avaliação das causas da intoxicação, principalmente, no tocante às tentativas de suicídio, para que o profissional de saúde consiga intervir não só no diagnóstico e tratamento adequado, mas na criação de políticas públicas eficazes, que consigam prever e reduzir a venda e o uso dos produtos tóxicos de forma indiscriminada.

\section{REFERÊNCIAS}

1. BAIOCCO GG, et al. Perfil dos pacientes com intoxicação medicamentosa atendidos na unidade de emergência de um hospital universitário. Revista Estácio Saúde, 2020; 9(2): 8-13.

2. BRASIL. Ministério da Saúde. 2020. Portaria №. 1061, de 18 de maio de 2020. Disponível em: https://www.in.gov.br/en/web/dou/-/portaria-n-1.061-de-18-de-maio-de-2020-259143078. Acesso em: 25 ago. 2020.

3. CARVALHO FSA, et al. Intoxicação exógena no estado de Minas Gerais, Brasil. C\&d-revista Eletrônica da Fainor, $2017 ; 10(1): 172-184$.

4. CEQUINEL JC e RODRIGO LCP. Material técnico de intoxicações agudas por agrotóxicos atendimento inicial do paciente intoxicado. Manual Técnico de Atendimento Ao Paciente Intoxicado. 2018; 1(2): 24-120.

5. FERREIRA DS, et al. Perfil das vítimas de intoxicações por agrotóxicos de um hospital geral em Dourados/MS de 2000 a 2010. Interbio, 2014; 8(1): 4-15.

6. FIOCRUZ, Fundação Oswaldo Cruz. 2010. Sistema nacional de informações tóxico-farmacológicas (SINITOX). Casos registrados de intoxicação humana por agente tóxico e centro. Disponível em: http://www.fiocruz.br/sinitox_novo/media/nd1.pdf. Acesso em: 24 set. 2020.

7. GONÇALVES CA, et al. Intoxicação medicamentosa: relacionada ao uso indiscriminado de medicamentos. Revista Cientifica Faculdade de Educação e Meio Ambiente, 2017; 8(1): 135-43.

8. GONÇALVES HC, et al. Intoxicação exógena: casos do estado de Santa Catarina no período de 2011 a 2015 . Arquivo Catarinense de medicina, 2018; 47(3): 02-15.

9. LIBERATO AA, et al. Intoxicações exógenas na região norte: atualização clínica e epidemiológica. Revista de Patologia do Tocantins, 2017; 4(2): 61-64.

10. LIMA JVO, et al. A importância da atenção farmacêutica na prevenção de intoxicações por medicamentos no estado do Piauí. Brazilian Journal of Surgery and Clinical Research (BJSCR), 2020; 29(2): 40-44. 
11. MELO CMD, et al. Óbitos violentos e tentativas de suicídio por intoxicação exógena em mulheres: eventos preditores da violência doméstica. Oikos: Família e Sociedade em Debate, 2020; 31(1): 7-39.

12. MORAES AL, et al. Automedicação: revisando a literatura sobre a resistência bacteriana aos antibióticos. Revista Eletrônica Estácio de Sá, 2016; 5(1): 122-32.

13. NAKAJIMA NR, et al. Análise epidemiológica das intoxicações exógenas no triângulo mineiro. Brazilian Journal Of Health And Biomedical Sciences, 2019; 18(2): 50-70.

14. OLIVEIRA FFS, SUCHARA EA. Perfil epidemiológico das intoxicações exógenas em crianças e adolescentes em município do Mato Grosso. Revista Paulista de Pediatria, 2014; 32 (4): 299-305.

15. PRÜSS-USTÜN A, et al. Knowns and unknowns on burden of disease due to chemicals: a systematic review. Environ Health, 2011; 10: 9.

16. R Development Core Team. 2020. A language and environment for statistical computing. R Foundation for Statistical Computing. Disponível em: http://www.R-project.org. Acesso em: 23 jan. 2020.

17. RANGEL NL, FRANCELINO EV. Caracterização do perfil das intoxicações medicamentosas no Brasil, durante 2013 a 2016. Id on Line Revista Multidisciplinar e de Psicologia, 2018; 12(42): 121-35.

18. REBELO FM, et al. Intoxicação por agrotóxicos no Distrito Federal, Brasil, de 2004 a 2007 - análise da notificação ao Centro de Informação e Assistência Toxicológica. Ciência \& Saúde Coletiva, 2011; 16(8): 3493-3502.

19. SANTOS AS, et al. Tentativas e suicídios por intoxicação exógena no Rio de Janeiro, Brasil: análise das informações através do linkage probabilístico. Cadernos de Saúde Pública, 2015; 30: 1057-1066.

20. SANTOS IND, et al. Implicações das intoxicações exógenas por agrotóxicos à saúde do trabalhador: uma revisão integrativa. Revista Ibero-Americana de Humanidades, Ciências e Educação, 2021; 7 (2):16-16.

21. SANTOS RR, et al. Perfil de vítimas de intoxicações exógenas agudas e assistência de enfermagem. Revista de Enfermagem e Atenção à Saúde, 2016; 4(2): 45-55.

22. SILVA RLF, et al. Perfil epidemiológico das intoxicações exógenas na cidade de Juiz de Fora - MG. Hu Revista, 2017; 43(2): 149-154.

23. SINAN, Sistema de Informação de Agravos de Notificação, 2019. Disponível em: http://dtr2004.saude.gov.br/sinanweb/novo/Documentos/SinanNet/fichas/violencia.pdf. Acesso em: 20 mai. 2020.

24. TIMÓTEO MVF, et al. Panorama das intoxicações associadas ao uso de medicamentos registradas no Brasil. Research, Society and Development, 2020; 9(4): 142942993-142942993.

25. VELOSO C, et al. Violência auto infligida por intoxicação exógena em um serviço de urgência e emergência. Revista Gaúcha de enfermagem, 2017; 38(2): 66187-66187.

26. VIEIRA D, CAVEIÃO C. Perfil Das Intoxicações Medicamentosas no Estado De São Paulo na Perspectiva Da Vigilância Sanitária. Revista Saúde e Desenvolvimento, 2016; 9(5):120-136.

27. VIEIRA LP, et al. Caracterização de tentativas de suicídios por substâncias exógenas. Caderno de Saúde Coletiva, $2015 ; 23(2): 118-123$. 